\title{
EFEITO DO SUBSTRATO E DA TEMPERATURA NA GERMINAÇÃO DE SEMENTES DE CATAIA (Drimys brasiliensis MIERS. WINTERACEAE) ${ }^{1}$
}

\author{
DANIELACLEIDEA. DEABREU²,ANTONIO CARLOS NOGUEIRA ${ }^{3}$, ANTONIO CARLOS DE SOUZAMEDEIROS $^{4}$
}

\begin{abstract}
RESUMO - O objetivo deste trabalho foi avaliar a germinação de sementes de cataia (Drimys brasiliensis) sob diferentes temperaturas e tempos de estratificação. As sementes foram submetidas ao método de estratificação em casa de vegetação, sem controle de temperatura, durante 30, 60 e 90 dias. Foram testados os substratos papel de filtro, areia, vermiculita e ágar a $1 \%$ e as temperaturas constantes de $17^{\circ} \mathrm{C}, 25^{\circ} \mathrm{C}$ e $30^{\circ} \mathrm{C}$, na presença de luz contínua e temperatura alternada de $20-30^{\circ} \mathrm{C}$, sendo $20^{\circ} \mathrm{C}$ por 16 horas no escuro e $30^{\circ} \mathrm{C}$ por 8 horas em presença de luz. O vigor foi avaliado por meio do índice de velocidade de germinação (I.V.G.). As sementes apresentaram grau de umidade inicial de 7\% (base úmida). Após 30, 60, 90 dias de estratificação o grau de umidade passou para $11,3 \%, 27,7 \%$ e $46,2 \%$, respectivamente. Os valores da porcentagem de germinação foram de $67 \%$ e $52 \%$ nos tratamentos com 30 e 60 dias de estratificação, respectivamente, obtidos na temperatura de $17^{\circ} \mathrm{C}$. Os valores de germinação obtidos com 30 dias de estratificação foram $68 \%$ para os substratos ágar, areia, e papel de filtro e $61 \%$ para o substrato vermiculita. No tratamento com 60 dias de estratificação, os valores de porcentagem de germinação foram $56 \%$, 58\% e 54\% nos substratos ágar, areia e papel de filtro, respectivamente, não diferindo estatisticamente entre si. As sementes mais vigorosas foram as estratificadas durante 60 dias e colocadas para germinar nos substratos ágar, areia e papel de filtro, na temperatura de $17^{\circ} \mathrm{C}$, onde foram obtidos os valores 0,55 , 0,61 e 0,65 para I.V.G., respectivamente. As sementes apresentam dormência por imaturidade embrionária e a estratificação em areia durante 60 dias é um método eficiente para superar a dormência das sementes de cataia. Os maiores valores de velocidade e percentagem de germinação em sementes de cataia são obtidos na temperatura constante de $17^{\circ} \mathrm{C}$ com o uso dos substratos ágar, areia e papel de filtro.
\end{abstract}

Termos para indexação: dormência embrionária, estratificação, viabilidade

\section{THE EFFECT OF SUBSTRATE AND TEMPERATURE ON CATAIA(Drimys brasiliensis Miers. WINTERACEAE) SEED GERMINATION}

\begin{abstract}
The aim of this research was to evaluate cataia (Drimys brasiliensis Miers. Winteraceae) seed germination under different, temperatures, substrate and stratification times. Seeds were submitted to stratification method in green house, without controlled temperature, during 30, 60 and 90 days. Filter paper, sand, vermiculite and agar 1\% were tested as substrates. Were compared constant temperatures of 17,25 and $30^{\circ} \mathrm{C}$ under light, and alternate temperatures treatments of $20-30^{\circ} \mathrm{C}$, adopting $20^{\circ} \mathrm{C}$ for 16 hours in absence of light and $30^{\circ} \mathrm{C}$ for 8 hours exposed to light. IVG (Germination Speed Index) was obtained additionally as a vigor test, by counting
\end{abstract}

\footnotetext{
${ }^{1}$ Submetido em 08/03/2004. Aceito para publicação em 19/10/2004. Parte da Dissertação de Mestrado em Silvicultura apresentada pelo primeiro autor.

${ }^{2}$ Bióloga, MSc. Bolsista CAPES, Cx. P. 319, 83411-000, Colombo - PR, daniela@cnpf.embrapa.br.
}

\footnotetext{
${ }^{3}$ Eng. Florestal, Dr., Prof., Depto de Ciências Florestais, UFPR, Curitiba, PR, nogueira@floresta.ufpr.br

${ }^{4}$ Eng. Agrônomo, Ph.D., Pesquisador da Embrapa-Florestas, medeiros@cnpf.embrapa.br
} 
normal seedlings everyday after sowing. Cataia seeds showed $7 \%$ of moisture content (wet basis) at the beginning of the experiment. After 30,60 and 90 days of sand stratification, these seeds presented $11,3 \%, 27,7 \%$ and $46,2 \%$ of moisture content, respectively. Treatments with 30 and 60 days of sand stratification at $17^{\circ} \mathrm{C}$ obtained the highest germination percentage, of $67 \%$ and $52 \%$, respectively. The highest percentage of germination was obtained after 30 days of sand stratification corresponding to $68 \%$ for substrates like agar, sand and filter paper, and $61 \%$ for vermiculite. For the treatment with 60 days of sand stratification, the highest germination percentages were $56 \%$, $58 \%$ and $54 \%$ in agar, sand and filter paper, respectively, without statistic difference. The vigor seeds (IVG) were those that were sand stratified for 60 days and were transferred to agar, sand and filter paper to germinate, at $17^{\circ} \mathrm{C}$, presenting germination rate of $0,55,0,61$ and 0,65 . It was possible to conclude that 60 days of sand stratification is an efficient method to broken cataia seed dormancy. The higher rate an percentage of germination were obtained at constant temperature of $17^{\circ} \mathrm{C}$ with agar, sand and filter paper as substrates.

Index terms: stratification, seed dormancy, viability.

\section{INTRODUÇÃO}

O estudo de métodos adequados em análises de sementes para as espécies florestais tem merecido atenção no meio científico, visando informações que expresse a qualidade fisiológica da semente, tanto para sua preservação, como a utilização dessas espécies vegetais com os mais variados interesses.

Para o manejo e conservação dessas espécies, ainda existentes, torna importante reunir informações que caracterizem os aspectos ecológicos para sua propagação. Apesar do aumento considerável no desenvolvimento de técnicas para permitir a expressão de melhorar o potencial germinativo das sementes, realizadas por meio de pesquisas nas últimas décadas, a maioria das espécies florestais nativas necessita de informações silviculturais, principalmente às relacionadas com as condições apropriadas para que suas sementes germinem. Tendo em vista estes aspectos, foi selecionada a espécie nativa Drimys brasiliensis Miers., conhecida como cataia. Esta espécie que apresenta interesse sócio-econômico, pela madeira de boa qualidade e com um vasto campo de aplicação industrial, desde bebidas e medicamentos, sendo ainda indicadas para arborização urbana e na recuperação de ecossistemas degradados (Lorenzi, 1992).

Drimys brasiliensis é o único gênero na América do Sul e na flora do Sul do Brasil, ocorrendo desde a Bahia até o Rio Grande do Sul, na Floresta Ombrófila Mista (Backes \& Nardino, 1998) e Floresta Estacional Semidecidual (Figliolia \& Piña-Rodrigues, 1995a) e Floresta Ombrófila Densa.

Estudos preliminares indicaram que as sementes de Drimys brasiliensis têm dormência, o que se constitui num problema para análise de sementes e a produção de mudas.
Diante do interesse em empregar essa espécie em plantios florestais e ampliar suas possibilidades de uso, é necessário buscar mais informações como, por exemplo, estabelecer as condições adequadas para a germinação das sementes e superação da dormência e com isto reduzir o tempo de produção de mudas. Dessa forma, este trabalho teve por objetivo avaliar o comportamento germinativo das sementes de Drimys brasiliensis sob diferentes temperaturas, substratos e tempo de estratificação e estabelecer a relação entre os resultados do teste de germinação em laboratório e o desenvolvimento embrionário nos diferentes tempos de estratificação.

\section{MATERIAL E MÉTODOS}

Os frutos de Drimys brasiliensis foram coletados em maio de 2001, de doze matrizes no município de Campina Grande do Sul - PR. A região é caracterizada por clima tipo Cfb (Köepen), uma altitude de $918 \mathrm{~m}$, a 25 29' $\mathrm{S}$ e $49^{\circ} 51^{\prime}$ $\mathrm{W}$, com precipitação média anual de $1458 \mathrm{~mm}$. O trabalho foi conduzido no Laboratório de Análise de Sementes do Centro Nacional de Pesquisa Florestal (Embrapa - Florestas).

Amostras de galhos com flores de D. brasiliensis foram herborizadas e secadas em estufa elétrica. As exsicatas se encontram no Herbário de curso de Engenharia Florestal da Universidade Federal do Paraná acondicionadas em latas de zinco e registradas sob o $\mathrm{n} .{ }^{\circ} \mathrm{EFC} 4643$.

Os frutos foram macerados e despolpados em água corrente para a obtenção das sementes. Em seguida, foram transferidos e espalhados sob peneiras contendo folhas de jornal durante 24 horas e secos na sobra. As sementes foram homogeneizadas, retirando-se amostras para a determinação 
da análise de pureza, peso de mil sementes, grau de umidade e comportamento germinativo.

Foram realizados estudos preliminares em diferentes combinações de substratos e temperaturas para avaliar a capacidade germinativa de sementes. Observou-se que a germinação dessas sementes foi muito baixa, quase nula, durante um longo período de semeadura. A incapacidade de germinação dessas sementes recém-colhidas é devido a uma dormência embrionária. Em função dos resultados preliminares de germinação, associadas às características morfológicas das sementes, utilizou-se o tratamento prégerminativo de estratificação para minimizar o período e uniformizar a germinação e a germinação foi avaliada em diferentes temperaturas e substratos.

As sementes de $D$. brasiliensis foram estratificadas na casa de vegetação da Embrapa-Florestas, em Colombo - PR, a partir de 14 de junho de 2001. A estratificação constituiu-se na colocação de uma camada de $5 \mathrm{~cm}$ de espessura de areia em caixas plásticas perfuradas em baixo. Foram colocadas 3.200 sementes (por tratamento) distribuídas sobre esta primeira camada de areia, cobertas com aproximadamente $10 \mathrm{~cm}$ de espessura de areia e umedecidas diariamente de forma que a areia se mantivesse sempre úmida. A estratificação foi realizada em três épocas, denominadas: época 1 (30 dias), época 2 (60 dias) e época 3 (90 dias).

Com sementes submetidas a 30 e 60 dias de estratificação, foram instalados os testes de germinação em diferentes temperaturas e substratos. Com 90 dias de estratificação, $51,28 \%$ das sementes germinaram durante o tratamento prégerminativo, inviabilizando a instalação dos mesmos.

A análise física foi realizada pela análise de pureza, peso de mil sementes, número de sementes por quilo e o grau de umidade, adotando-se as Regras para Análises de Sementes (Brasil, 1992). Para o cálculo do peso de mil sementes foram utilizadas oito amostras de 100 sementes e calculado o coeficiente de variação. A determinação do grau de umidade das sementes foi obtido pelo método de estufa à $105^{\circ} \mathrm{C} \pm 3^{\circ} \mathrm{C}$ durante 24 horas (Brasil, 1992). Utilizaram-se três amostras de 100 sementes, equivalente a 0,45 g cada.

Foram testadas três temperaturas constantes $\left(17^{\circ} \mathrm{C}, 25^{\circ} \mathrm{C}\right.$ e $30^{\circ} \mathrm{C}$ ) na presença de luz contínua e uma alternada $(20$ $30^{\circ} \mathrm{C}$ ), sendo $20^{\circ} \mathrm{C}$ durante 16 horas no período noturno (sem luz) e $30^{\circ} \mathrm{C}$ durante 8 horas no período diurno (com luz).

Nas temperaturas constantes foram utilizados os germinadores do tipo Mangelsdorf e para a temperatura alternada foi utilizada câmara de germinação tipo B.O.D. MA 402.
Para esterilização dos germinadores, colocou-se em cada germinador uma placa de petri, contendo formol (HCHO), mantendo-os fechados à temperatura de $30^{\circ} \mathrm{C}$ por 24 horas, conforme prescrições e recomendações de Figliolia \& PiñaRodrigues (1995b).

Quanto ao substrato foram testados: papel de filtro (SP), areia (SA), vermiculita (SV) e ágar (AG). A areia foi autoclavada durante duas horas, permanecendo em repouso durante 24 horas, para retirada do excesso de umidade. Após esse procedimento foi colocada em estufa à $110^{\circ} \mathrm{C}$ durante 24 horas para a secagem. Em seguida, foi peneirada em malha 1,7 mm, sendo utilizada a granulometria inferior. Para a vermiculita foi utilizada a granulometria média. Os substratos papel de filtro e a vermiculita foram esterilizados em estufa à $110^{\circ} \mathrm{C}$ por um período de 24 horas. $\mathrm{O}$ ágar foi preparado à concentração de 1\% (p/v) conforme Medeiros (1996).

Os substratos papel de filtro, areia, vermiculita e ágar foram colocados em caixas plásticas "gerbox". Para o substrato papel de filtro foram utilizadas duas folhas em cada caixa e umedecidos com $20 \mathrm{~mL}$ de água destilada. Para o substrato areia foram pesados $245 \mathrm{~g}$ e para a vermiculita 20 g. A estes substratos foram acrescidos $40 \mathrm{~mL}$ de água destilada. A umidade foi mantida adicionando-se água destilada sempre, que necessário. Para o substrato ágar utilizou-se aproximadamente $4 \mathrm{~mm}$ de espessura em cada gerbox.

A avaliação da porcentagem de germinação e do índice de velocidade de germinação foi realizada três vezes por semana. O teste de germinação foi encerrado quando se observou que as sementes não germinavam mais ou estavam em estado de deterioração. Após o encerramento do teste de germinação avaliaram-se as porcentagens de sementes deterioradas e as diferentes fases de desenvolvimento dos embriões. Foram consideradas germinadas as sementes que apresentaram emissão de radícula, com no mínimo $2 \mathrm{~mm}$.

Os embriões foram classificados quanto à forma para verificar o grau de maturidade da semente. Para isso, foram utilizadas sementes antes da instalação do teste de germinação e que foram estratificadas nas diferentes épocas citadas anteriormente. Para 30 dias de estratificação não foi possível determinar os estágios de desenvolvimento, devido ao número insuficiente de sementes.

Para a porcentagem de embriões nos diferentes estágios de desenvolvimento foram utilizadas 100 sementes para cada tratamento. Foram realizados cortes longitudinais nas sementes não germinadas. Estas foram colocadas em lâminas e examinadas quanto à forma e ao tamanho do embrião, com auxílio de uma ocular micrométrica, em microscópio 
estereoscópico, em aumento de três vezes, sendo as medidas transformadas em milímetros. A avaliação quanto à forma, baseou-se nos trabalhos de Heuser (1990) e Catapan (1998).

$\mathrm{O}$ teste de germinação e o índice de velocidade de germinação das sementes de $D$. brasiliensis em diferentes combinações de temperatura e substrato foram analisados em delineamento inteiramente casualizado em esquema fatorial de $2 \times 4 \times 4$ (época $\times$ temperatura $\times$ substrato), com 7 repetições de 25 sementes cada.

No cálculo do índice de velocidade de germinação foi empregada a fórmula de Maguire (1962), citada por Nakagawa (1994):

$\mathrm{IVG}=\mathrm{G} 1 / \mathrm{N} 1+\mathrm{G} 2 / \mathrm{N} 2+\ldots+\mathrm{Gn} / \mathrm{Nn}$; onde

$\mathrm{IVG}=$ índice de velocidade de germinação;

$\mathrm{G} 1, \mathrm{G} 2, \mathrm{Gn}=$ número de sementes germinadas computadas na primeira contagem, na segunda contagem e na última contagem.

$\mathrm{N} 1, \mathrm{~N} 2, \mathrm{Nn}=$ número de dias de semeadura à primeira, segunda e última contagem.

Foi realizado o teste de Hartley para verificar a homogeneidade de variância segundo Banzatto \& Kronka (1995). Os dados que não apresentavam homogeneidade de variância e distribuição normal foram transformados segundo $\operatorname{arc~sen} \sqrt{X / 100}$ Efetuou-se a Anova e para a comparação entre as médias, adotou-se o teste de Duncan, ao nível de 5\% de probabilidade. As médias dos tratamentos nas tabelas são apresentadas em valores originais. Foi utilizado o Sistema de Análise Estatística - SANEST e para a elaboração dos gráficos o programa Excel versão 5.0.

\section{RESULTADOS E DISCUSSÃO}

Na Figura 1 estão apresentadas as porcentagens de embriões de D. brasiliensis, nas formas: globular, coração, torpedo e maduro, avaliados em sementes sem estratificação, com 60 e 90 dias de estratificação. Não foram avaliadas as diferentes fases de desenvolvimento embrionário, com 30 dias de estratificação, devido ao número insuficiente de sementes. Observou-se que na amostragem de sementes sem estratificação $6 \%$ dos embriões encontravam-se em forma globular e $94 \%$ na de coração. Após 60 dias de estratificação, foram encontrados $9 \%$ de embriões em forma de coração, $8 \%$ de torpedo e $83 \%$, maduro. Com 90 dias de estratificação $14 \%$ estavam na forma de coração, $15 \%$ na forma de torpedo e $71 \%$ já estavam maduros.

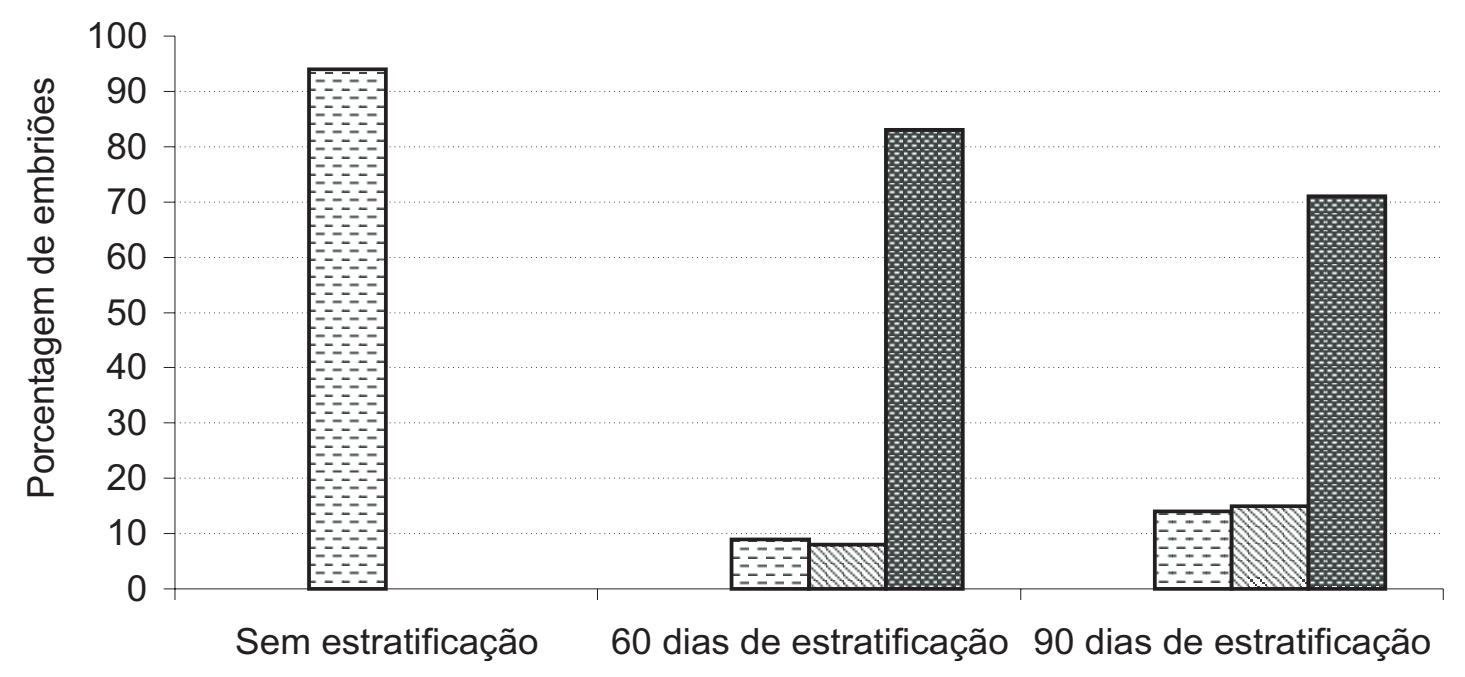

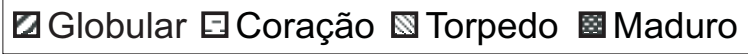

FIGURA 1. Porcentagem de embriões de Drimys brasiliensis em diferentes fases de desenvolvimento. 
Nota-se que ocorreu um incremento na porcentagem de embriões na forma de maduro, nos períodos de 60 e 90 dias de estratificação, quando comparados com as sementes sem estratificação, com maior porcentagem de embriões na forma de coração. Observou-se também que houve diferença na porcentagem de embriões na forma de maduro entre 60 e 90 dias estratificação, com valores de $83 \%$ e $71 \%$, respectivamente. Provavelmente, o maior período de estratificação, fez com que ocorresse maior número de embriões desenvolvidos, promovendo a germinação e reduzindo a quantidade de embriões maduros, entre os tratamentos, pois, verificou-se que 51\% das sementes germinaram durante os 90 dias em que ficaram estratificadas (Figura 1).

De acordo com Cunha (1990), a forma dos embriões é utilizada para determinar os estágios de desenvolvimento dos mesmos, sendo o desenvolvimento embrionário de Capsella bursa-pastoris utilizada como padrão para estudos de embriogênese de dicotiledôneas. O desenvolvimento de embriões inicia-se pela formação de uma massa de células de forma globular, passando para a forma de coração e, seqüencialmente pelos estágios de torpedo e maduro, quando então, é considerado apto para germinar (Cunha, 1990).

Os dados obtidos na Figura 1 indicam que não há sincronia no desenvolvimento morfológico entre o fruto e o embrião, isto é, quando os frutos já estão maduros, os embriões ainda se encontram na fase rudimentar no momento da dispersão. Portanto, os embriões de D. brasiliensis são rudimentares e necessitam de um período adicional para completar seu desenvolvimento antes de se tornarem aptos para germinar. Essa constatação concorda com o observado por Catapan (1998), citando que a ocorrência de diferentes formas de embriões nas sementes e o conhecimento do seu desenvolvimento contribui para a identificação das causas de dormência de algumas espécies.

Considerando que, na maioria das sementes, no momento da coleta do fruto, os embriões se encontravam na forma de coração com 94\% e 6\% na forma globular (Figura 1), sugerese que a dormência se instala na forma de coração, quando os frutos ainda se encontram na planta-mãe. Trabalhos semelhantes foram encontrados para Ilex paraguariensis, onde Heuser (1990) sugere que os embriões entram em dormência no estágio de coração. Dessa forma, a baixa germinação de D. brasiliensis encontrada nos estudos preliminares em diferentes combinações de substratos e temperaturas, associadas às características morfológicas do embrião e os dados obtidos neste trabalho, permitem afirmar que o tratamento pré-germinativo de estratificação promove o desenvolvimento embrionário, superando a dormência dessas sementes. O)s resultados obtidos neste trabalho discordam de Figliolia e Piña-Rodrigues (1995a), que recomendam para Drimys brasiliensis, como tratamento pré-germinativo, o corte ou lixamento do tegumento da semente ou do fruto.

O resultado da análise de pureza para $D$. brasiliensis foi de $66 \%$. Obteve-se peso de mil sementes de $4,21 \mathrm{~g}$ e grau de umidade de 7,1\%, assim um quilo de sementes apresenta 237.353 unidades, contrastando com os resultados obtidos por Figliolia \& Piña-Rodrigues (1995a) que encontraram o valor de 16.000, Longhi (1995) obteve 280.000 e Lorenzi (1992) 218.000 sementes.

O grau de umidade das sementes, após 30,60 e 90 dias de estratificação, foi de $11,3 \%, 27,7 \%$ e $46,2 \%$, respectivamente. Esta variação nos valores foi ocasionada pelo aumento da absorção de água, durante o período de estratificação.

Na Tabela 1, analisando a interação entre época e temperatura, observou-se que os maiores valores de porcentagem de germinação foram de $67 \%$ e $52 \%$ obtidos a temperatura de $17^{\circ} \mathrm{C}$, nos tratamentos com 30 e 60 dias de estratificação, respectivamente. Porém diferem estatisticamente entre si. Os resultados obtidos demonstram que $D$. brasiliensis, necessita de temperatura mais baixa para que ocorra a germinação, pois as temperaturas constantes de $25^{\circ} \mathrm{C}$ e $30^{\circ} \mathrm{C}$ e alternada de $20-30^{\circ} \mathrm{C}$ demonstram ser inadequadas para a germinação. Isto pode ser constatado pela redução na porcentagem de sementes germinadas, quando submetidas nessas condições (Tabela 2).

A necessidade de algumas sementes passarem por um período de frio para superar a dormência é um mecanismo que evita a exposição das plântulas à baixa temperatura, o que seria potencialmente danoso (Bryant, 1985). No caso de $D$. brasiliensis, por ser uma espécie andina, não necessita desenvolver mecanismos fisiológicos de adaptação em climas frios, portanto, um período de estratificação é o suficiente para que a dormência seja superada e as sementes germinem no inverno.

Visto que as sementes de $D$. brasiliensis necessitam da temperatura de $17^{\circ} \mathrm{C}$ para germinar, observou-se na interação temperatura e substrato, que com 30 dias de estratificação, independente do substrato utilizado e, com 60 dias de estratificação em substratos ágar e areia, apresentaram as melhores porcentagens de germinação, igualando-se estatisticamente. Por outro lado, com 30 de estratificação, as menores médias foram obtidas em temperatura de $25^{\circ} \mathrm{C}$, com 
porcentagens de $1 \%, 3 \% 6 \%$ e $6 \%$ de germinação, em substratos vermiculita, areia, papel de filtro e ágar, respectivamente (Tabela 2 ).

Os dados obtidos indicam que, além da temperatura, o substrato empregado, também agiu de forma diferenciada no resultado do comportamento germinativo. Segundo Figliolia et al. (1993), a vermiculita vem sendo utilizada com bons resultados para as espécies florestais devido sua boa capacidade de absorção, retenção de água, sendo também indicada para sementes com germinação lenta. Para D. brasiliensis, no entanto, o uso de vermiculita associada aos 60 dias de estratificação, mostrou-se inadequado, produzindo $40 \%$ de germinação. Este valor foi inferior aos obtidos nos demais substratos e, provavelmente, o tamanho da semente e a sua exigência com relação à água, não foram compatíveis com as características físicas do substrato, influenciando negativamente na germinação. O uso de papel de filtro, apesar de ser indicado para sementes pequenas e de rápida germinação (Figliolia \& Pinã-Rodrigues, 1995a), tende a favorecer o desenvolvimento de microrganismos aeróbicos (Figliolia et al., 1993).

O ágar é considerado como um excelente substrato, porém observou-se que, nas temperaturas de $25^{\circ} \mathrm{C}$ e $30^{\circ} \mathrm{C}$ houve desidratação do mesmo, durante o período de semeadura, o que pode ser justificado pelo longo período de permanência das sementes nos germinadores. Essas características do substrato concordam com Catapan (1998) que, trabalhando com sementes de Ilex paraguariensis, também observou rápida desidratação em temperaturas acima de $25^{\circ} \mathrm{C}$, além de favorecer a contaminação por microrganismos. Portanto, entre os substratos estudados, verificou-se que a areia, mantida em temperatura constante de $17^{\circ} \mathrm{C}$ foi o substrato mais adequado para a germinação de sementes de $D$. brasiliensis, uma vez que ele é indicado para todo tipo de sementes, até para as espécies mais sensíveis ao ressecamento e que exigem um período mais prolongado para germinarem.

Pode-se se observar na Tabela 2, que os maiores valores do índice de velocidade de germinação para $D$. brasiliensis, foi obtido com 60 dias de estratificação, nos substratos ágar, areia e papel de filtro, atingindo os valores de 0,55 0,61 e 0,65 , respectivamente, diferindo estatisticamente dos demais tratamentos.

Na interação época e temperatura na Tabela 3, observouse que o maior índice de velocidade de germinação foi obtido com 60 dias de estratificação, nas temperaturas de $17^{\circ} \mathrm{C}, 25^{\circ} \mathrm{C}$ e $30^{\circ} \mathrm{C}$, atingindo os valores de $0,63,0,55$ e 0,52 , respectivamente, igualando-se estatisticamente. No entanto, verifica-se que a obtenção de um melhor índice de velocidade de germinação para as sementes de $D$. brasiliensis, não depende apenas do período de permanência na estratificação, mas também das condições em que são colocadas para germinar, como o substrato e a temperatura. Portanto, os dados obtidos entre os diferentes tratamentos, indicam que para alcançar o melhor índice de velocidade de germinação para as sementes de D. brasiliensis, as mesmas devem ser estratificadas por um período de 60 dias e submetidas à temperatura de $17^{\circ} \mathrm{C}$, e como substratos, recomenda-se o ágar, a areia e o papel de filtro.

TABELA 1. Porcentagem de germinação de sementes de Drimys brasiliensis, em diferentes temperaturas, com 30 e 60 dias de estratificação.

\begin{tabular}{lllllc}
\hline \multirow{2}{*}{ ÉPOCAS } & \multicolumn{4}{c}{ TEMPERATURA $\left({ }^{\circ} \mathrm{C}\right)$} \\
\cline { 2 - 6 } & 17 & 25 & 30 & $20-30$ & Médias \\
\hline 30 dias de estratificação & $67 \mathrm{aA}$ & $3 \mathrm{bC}$ & $25 \mathrm{aB}$ & $22 \mathrm{aB}$ & 29 \\
60 dias de estratificação & $52 \mathrm{bA}$ & $27 \mathrm{aB}$ & $25 \mathrm{aBC}$ & $21 \mathrm{aC}$ & 31 \\
\hline Média & 59 & 15 & 25 & 21 & 30 \\
\hline
\end{tabular}

Médias seguidas por letras iguais minúsculas na mesma coluna e maiúscula na mesma linha, não diferem entre si, ao nível de $5 \%$ pelo teste de Duncan.

TABELA 2. Porcentagem de germinação de sementes de Drimys brasiliensis em diferentes temperaturas e substratos com 30 e 60 dias de estratificação.

\begin{tabular}{|c|c|c|c|c|c|c|c|c|}
\hline \multirow{3}{*}{ SUBSTRATO } & \multicolumn{8}{|c|}{ TEMPERATURA $\left({ }^{\circ} \mathrm{C}\right)$} \\
\hline & \multicolumn{2}{|c|}{17} & \multicolumn{2}{|c|}{25} & \multicolumn{2}{|c|}{30} & \multicolumn{2}{|c|}{$20-30$} \\
\hline & E1 & E2 & E1 & E2 & E1 & E2 & E1 & E2 \\
\hline Agar & $68 \mathrm{aA}$ & $56 \mathrm{aA}$ & $6 \mathrm{bA}$ & $33 \mathrm{aA}$ & $17 \mathrm{aB}$ & $17 \mathrm{aB}$ & $21 \mathrm{aA}$ & $21 \mathrm{aA}$ \\
\hline Areia & 69 aA & 58 aA & $3 \mathrm{bAB}$ & 30 aA & 36 aA & 36 aA & 19 aA & 19 aA \\
\hline Vermiculita & 62 aA & $40 \mathrm{bB}$ & $1 \mathrm{bB}$ & 23 aA & $18 \mathrm{aB}$ & $19 \mathrm{aB}$ & 26 aA & $20 \mathrm{aA}$ \\
\hline Papel de filtro & $69 \mathrm{aA}$ & $54 \mathrm{bA}$ & $6 \mathrm{bA}$ & $25 \mathrm{aA}$ & $28 \mathrm{aAB}$ & $28 \mathrm{aAB}$ & $23 \mathrm{aA}$ & $23 \mathrm{aA}$ \\
\hline Média & 67 & 52 & 4 & 28 & 25 & 25 & 22 & 20 \\
\hline
\end{tabular}

E1=30 dias de estratificação e E2 = 60 dias de estratificação. Médias seguida por letras iguais minúsculas na mesma linha e maiúsculas na mesma coluna entre as épocas (E1 e E2) não diferem entre si, ao nível de 5\%, pelo teste de Duncan. 
As porcentagens acumuladas de germinação sob temperatura de $17^{\circ} \mathrm{C}$, realizadas nas diversas combinações de substrato, para as sementes estratificadas, com 30 e 60 dias, estão representadas nas Figuras 2 e 3, respectivamente.

Observa-se pela Figura 2, que no substrato areia, não houve germinação até aos 43 dias de semeadura, enquanto que nos substratos ágar, papel de filtro e vermiculita, com o mesmo período de semeadura, ocorre a germinação, porém a quantidade de sementes germinadas é pequena. Quando o teste de germinação foi encerrado aos 81 dias, observou-se que a germinação no substrato areia atingiu a média de $69 \%$, igualando-se estatisticamente aos substratos ágar, papel de filtro e vermiculita com valores de $68 \%$, 69\% e $62 \%$ de germinação.

Observou-se que após 30 dias de estratificação, a germinação foi lenta, indicando que as sementes necessitam de um tempo maior de exposição à estratificação antes de serem capazes de germinar. A baixa porcentagem de germinação, obtida inicialmente indica que nas sementes que germinaram primeiro os embriões estavam mais desenvolvidos, no estádio maduro. No início da curva, os embriões estavam no estádio de torpedo e, em seguida, quando a curva ganha uma inclinação acentuada, os embriões estão na fase de coração. Mesmo que os embriões estejam completamente maduros, o substrato é um fator importante, tanto para a velocidade quanto para porcentagem de germinação, pois verificou-se que a germinação é lenta e mais baixa, quando as sementes são colocadas em vermiculita (Figura 2).

Embora tenha havido maior porcentagem de sementes germinadas aos 30 dias de estratificação, em relação ao tratamento de 60 dias, observa-se que houve redução no tempo entre a semeadura e o início da germinação com 60 dias de estratificação, pois com 30 dias, a curva somente passou a ganhar um incremento acentuado a partir dos 43 dias após a semeadura, finalizando aos 81 dias (Figura 2). No tratamento com 60 dias de estratificação, a curva ganha um incremento aos 6 dias, finalizando aos 51 dias após a semeadura (Figura 3).

TABELA 3. Índice de velocidade de germinação de sementes de Drimys brasiliensis diferentes substratos, com 30 e 60 dias de estratificação.

\begin{tabular}{cccccc}
\hline \multirow{2}{*}{ ÉPOCA } & \multicolumn{5}{c}{ SUBSTRATO } \\
\cline { 2 - 6 } & ÁGAR & AREIA & PAPEL DE FILTRO & VERMICULITA & Média \\
\hline 30 dias de estratificação & $0,12 \mathrm{bA}$ & $0,10 \mathrm{bA}$ & $0,10 \mathrm{bA}$ & $0,11 \mathrm{bA}$ & 0,10 \\
60 dia s de estratificação & $0,54 \mathrm{aA}$ & $0,61 \mathrm{aA}$ & $0,70 \mathrm{aA}$ & $0,30 \mathrm{aB}$ & 0,53 \\
\hline Média & 0,33 & 0,35 & 0,40 & 0,20 & 0,31 \\
\hline
\end{tabular}

Médias seguida por letras iguais minúsculas na mesma coluna e maiúscula na mesma linha, não diferem entre si ao nível de 5\%, pelo teste de Duncan.

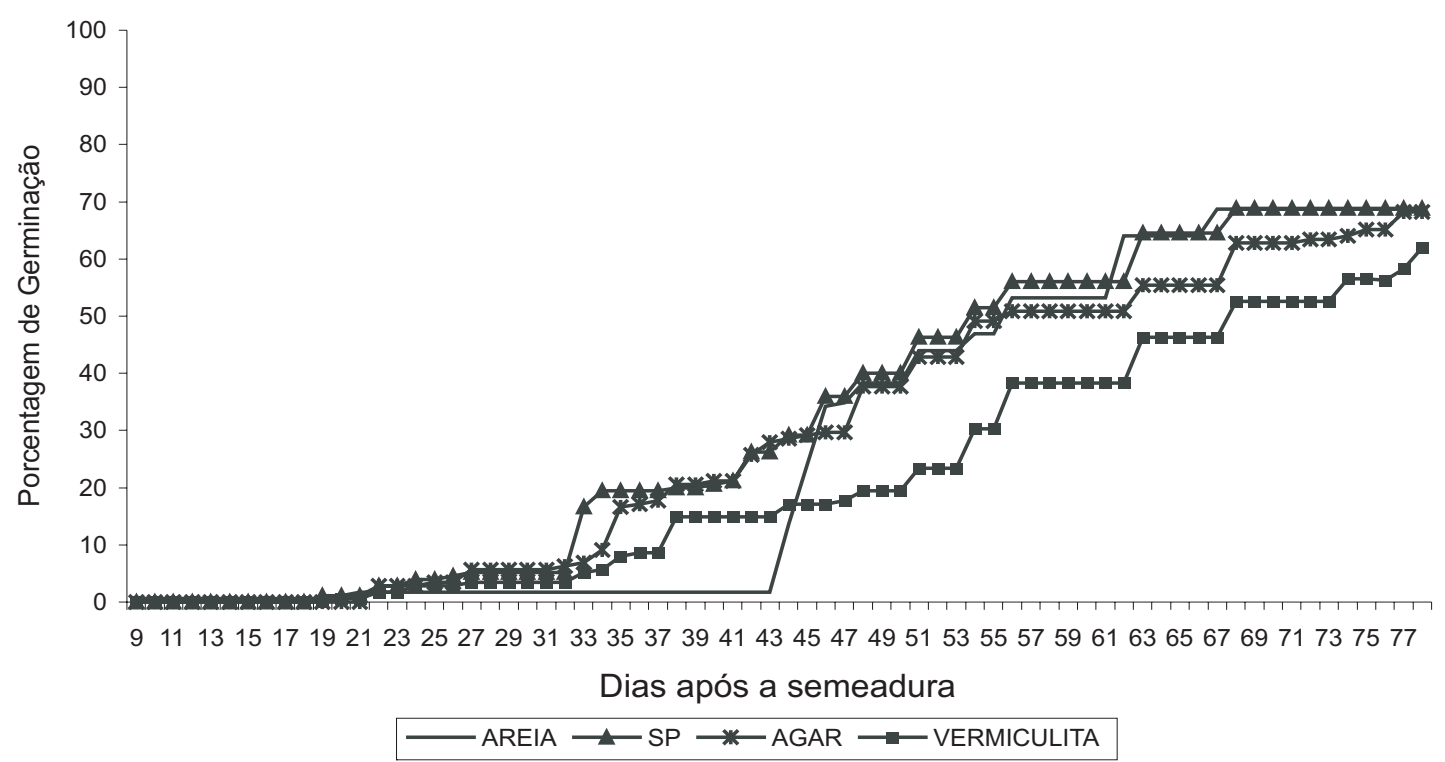

FIGURA 2. Porcentagem acumulada de germinação de sementes de Drimys brasiliensis sob temperatura de $17^{\circ} \mathrm{C}$, em diferentes substratos, estratificadas no período de 30 dias. 


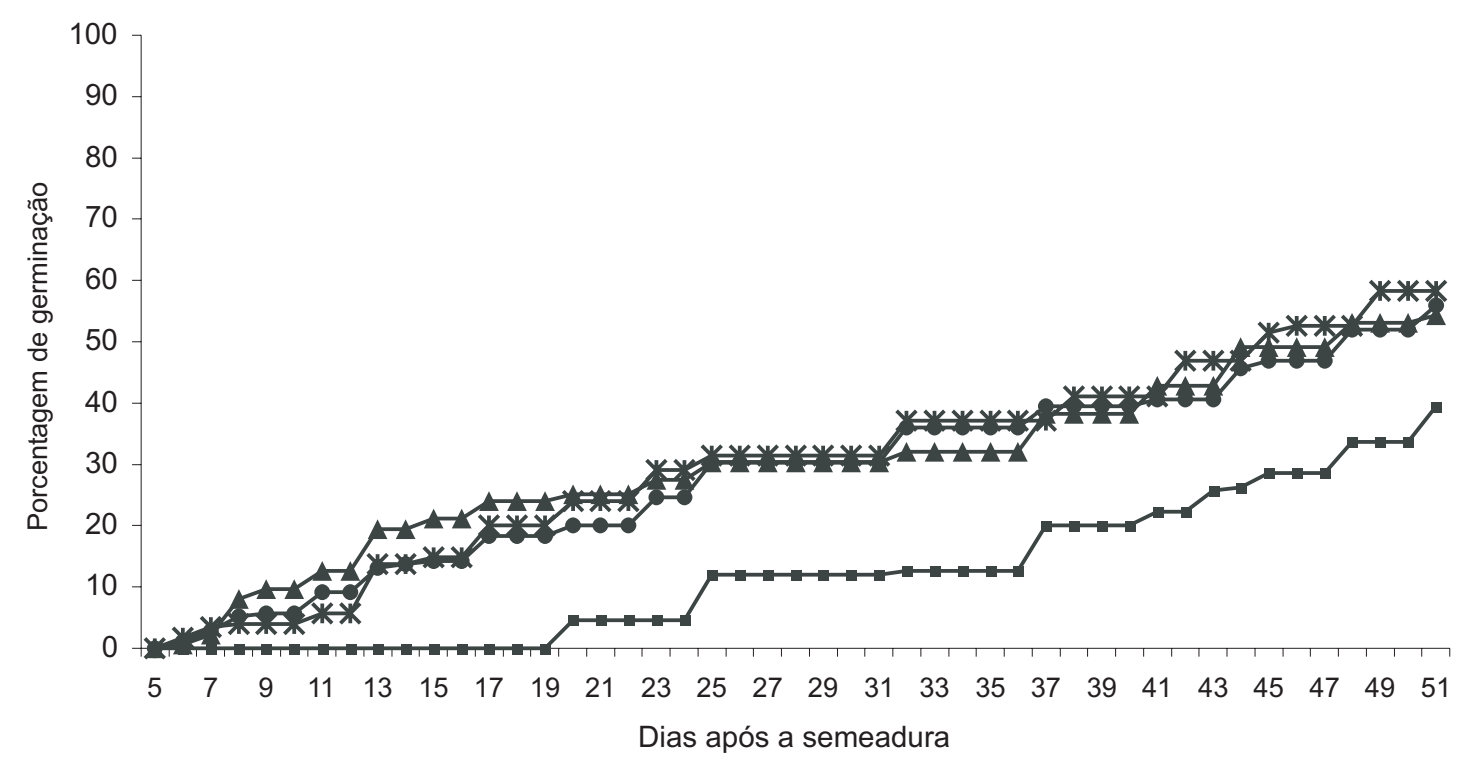

FIGURA 3. Porcentagem acumulada de germinação de sementes de Drimys brasiliensis sob temperatura de $17^{\circ} \mathrm{C}$, em diferentes substratos, estratificadas no período de 60 dias.

Para superar a dormência e completar o desenvolvimento dos embriões de Drimys brasiliensis, são necessários 60 dias de estratificação. Dessa forma, o teste de germinação pode ser instalado em substratos ágar, areia ou papel de filtro sob temperatura de $17^{\circ} \mathrm{C}$. Nessas condições a germinação tem início aos seis dias e pode ser encerrada aos 51 dias após a semeadura (Figura 3).

Pode-se observar na Tabela 4 que houve alta porcentagem de sementes deterioradas nos tratamentos com temperaturas de $25^{\circ} \mathrm{C}$ e $30^{\circ} \mathrm{C}$ em 30 dias de estratificação.

Em algumas espécies florestais, a estratificação em baixas temperaturas, pode reduzir a sensibilidade das sementes às condições externas, ampliando a faixa de temperatura sob a qual germinação poderá ocorrer. As sementes de Pinus lambertina somente germinam a temperaturas acima de $25^{\circ} \mathrm{C}$, mas, após a estratificação elas são capazes de germinar em temperaturas mais baixas (Malavasi, 1988). No caso de Drimys brasiliensis, mesmo após a estratificação, as sementes necessitam de temperaturas mais baixas para a germinação, pois quando submetidas a temperaturas mais altas, perderam a viabilidade.

TABELA 4. Porcentagem de sementes deterioradas de Drimys brasiliensis em diferentes temperaturas e substratos com 30 e 60 dias de estratificação.

\begin{tabular}{cccccc}
\hline ÉPOCA & \multicolumn{5}{c}{ TEMPERATURA $\left({ }^{\circ} \mathrm{C}\right)$} \\
\cline { 2 - 7 } & 17 & 25 & 30 & $20-30$ & Média \\
\hline 30 Dias de estratificação & $24 \mathrm{bC}$ & $73 \mathrm{aA}$ & $74 \mathrm{aA}$ & $62 \mathrm{aB}$ & 58 \\
60 Dias de estratificação & $41 \mathrm{aD}$ & $58 \mathrm{bC}$ & $67 \mathrm{bA}$ & $61 \mathrm{aB}$ & 56 \\
\hline Média & 32 & 65 & 70 & 61 & 57 \\
\hline
\end{tabular}

\section{CONCLUSÕES}

As sementes de Drimys brasiliensis têm dormência por imaturidade embrionária.

As sementes sem estratificação apresentam maior porcentagem de embriões codiformes. A estratificação em areia por 60 dias é eficiente para superar a dormência das sementes. Em temperatura constante de $17^{\circ} \mathrm{C}$ e com o uso dos substratos ágar, areia e papel de filtro, obtêm-se maiores valores de velocidade e percentagem de germinação.

Temperaturas de $25^{\circ} \mathrm{C}$ e $30^{\circ} \mathrm{C}$ são inadequadas para a germinação das sementes. 


\section{AGRADECIMENTOS}

Os autores agradecem o Centro Nacional de Pesquisas Florestais (CNPF) - Embrapa-Florestas por todo apoio e a concessão da infra-estrutura laboratorial na execução deste trabalho. À Universidade Federal do Paraná, pela realização do curso e a CAPES, pela concessão da bolsa de estudos.

\section{REFERÊNCIAS}

BACKES, A.; NARDINO, M. Árvores, arbustos e algumas lianas nativas no Rio Grande do Sul. São Leopoldo: UNISINOS, 1998. 202 p.

BANZATTO, D.A.; KRONKA, S. N. Experimentação agrícola. 3. ed. Jaboticabal: FUNEP, 1995. 274 p.

BRASIL. Ministério da Agricultura e Reforma Agrária. Regras para análises de sementes. Brasília: SNDA/DNDV/CLAV. 1992. $365 \mathrm{p}$.

BRYANT, J. A. Fisiologia da semente. São Paulo: EPU, 1989. 86 p. Temas de Biologia, 31.

CATAPAN, M.I.S. Influência da temperatura, substrato e luz na germinação de sementes de Ilex paraguariensis St. Hil. 1998. 97 f. Dissertação (Mestrado em Ciências Florestais) - Departamento de Engenharia Florestal, Universidade Federal do Paraná, Curitiba, 1998.

CUNHA, G. G. Cultura de embriões de erva-mate (Ilex paraguariensis St. Hil.) "in vitro". 1990. 51 f. Dissertação (Mestrado em Botânica) - Departamento de Ciências Biológicas, Universidade Federal do Rio Grande do Sul, Porto Alegre, 1990.
FIGLIOLIA, M.B.; OLIVEIRA, E.C.; PIÑA-RODRIGUES, F.C.M. Análise de sementes. In: AGUIAR, I.B.; PIÑA-RODRIGUES, F.C.M. (Coord.). Sementes Florestais Tropicais. Brasília: ABRATES, 1993. p. 137-174.

FIGLIOLIA, M.B.; PIÑA-RODRIGUES, F.C.M. Considerações práticas sobre o teste de germinação. Instituto Florestal. Série registros, São Paulo, n. 14, p. 45-60, 1995a.

FIGLIOLIA, M.B.; PIÑA-RODRIGUES, F. C. M. Manejo de sementes de espécies arbóreas. Instituto Florestal. Série registros, São Paulo, n. 14, p. 1-56, 1995 b.

HEUSER, E.D. Ilex paraguariensis St. Hil. Endosperma e embrião durante a embriogênese tardia. 1990. 76 f. Dissertação. (Mestrado em Botânica) - Departamento de Ciências Biológicas, Universidade Federal do Rio Grande do Sul, Porto Alegre, 1990.

LONGHI, R.A. Livro das árvores e arvoretas do sul. Porto Alegre: L \& PM, 1995. 176 p.

LORENZI, H. Árvores brasileiras: manual de identificação e cultivo de plantas arbóreas nativas do Brasil. Nova Odessa: Plantarum, 1992. $368 \mathrm{p}$.

MALAVASI, M.M. Germinação de sementes florestais. In: PIÑARODRIGUES, F. C. (Coord.) Manual de análise de sementes florestais. Campinas: Fundação Cargill, 1988. p. 25-40.

MEDEIROS, A.C. S. Comportamento fisiológico, conservação de germoplasma a longo prazo e previsão de longevidade de sementes de aroeira (Astronium urundeuva (Fr. All.) Engl.). 1996. $146 \mathrm{f}$. Tese (Doutorado em Produção Vegetal) - Faculdades de Ciências Agrárias e Veterinárias, Universidade Estadual Paulista, Jaboticabal, 1996.

NAKAGAWA, J. Testes de vigor baseados na avaliação das plântulas. In: VIEIRA, R. D.; CARVALHO, N. M. (Ed.). Testes de vigor em sementes. Jaboticabal: FUNEP, 1994. p. 49-86.

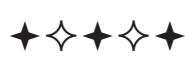

